whether or not some of their incidental findings can be applied for offensive purposes-any scientist's published work may be so used. The work of the MRE is entirely subject to Government policy and has been uniformly accepted by successive Governments since the Second World War. Mr Clarke feels that the presence of virulent organisms at MRE might lead us into offensive work-but, of course, many other laboratories in Britain (particularly public health laboratories) possess as many pathogens as we do.

The possible prevention of $\mathrm{C}$ and $\mathrm{BW}$ by international agreement or other means is discussed. The Geneva Protocol has been apparently effective-perhaps rather because of a general lack of desire, or a general fear, of using these weapons rather than because of the Protocol. In any case, a nation under severe pressure may not regard the Protocol as a serious barrier to the use of weapons they consider necessary to win a war. Britain has just taken a welcome initiative in Geneva to try to obtain a clearer, more restrictive and realistic agreement to international abrogation of $\mathrm{BW}$ in the hope, which we must all share, that the use of $\mathrm{BW}$ can be indefinitely prevented. A solid advance in the control of the use of these weapons is, however, likely to hang on an ability to create a credible inspection and verification system. While the Pugwash visitations described by $\mathbf{M r}$ Clarke have been encouraging, they do not go far towards the objective, and the idea of detection systems for longdistance monitoring of trial activities barely holds water at present in view of the difficulty of large defence organizations in elaborating satisfactory automatic alarm systems for detection fairly close to the source of an attack. Mr Clarke's alternative approach is to seek declassification of all work on B and CW (but not other forms of warfare). He admits that to stop the research would be unacceptable because of its great general value. He takes the rather ingenuous view that if the inoffensive British effort were declassified the United States and the Soviet Union might follow suit. British work is withheld from publication only if it would confer an advantage on an aggressor, thereby increasing the threat to the British people. This basis is accepted by the staffs of both the MRF and CDEE and by their independent advisers, and I know of no cases where Mr Clarke would be justified in saying that this situation "has caused the resignation of a number of microbiologists". The argument that because research is defensive it should all be disclosed does not withstand critical thought. To fully reveal our state of readiness or unreadiness to defend ourselves would surely be unwise.

While every effort to prevent war, and $\mathrm{C}$ and $\mathrm{BW}$ in particular, should continue as vigorously as possible, one must conclude with Merck (quoted by Mr Clarke) that in present circumstances "any method which appears to offer advantages to a nation at war will be vigorously employed by that nation. There is but one logical course to pursue, namely, to study the possibilities of such warfare from every angle, make every preparation for reducing its effectiveness, and thereby reduce the likelihood of its use".

\section{ERADICATING PESTS}

Principles of Insect Chemosterilization

Edited by G. C. La Brecque and C. H. Smith. Pp. viii 354. (Appleton-Century-Crofts: New York, 1968.) \$16.

THE successful eradication of populations of the screw worm fly (Cochliomyia hominivorax Coq.) by the release of male flies sterilized by gamma irradiation stimulated research into chemosterilants as an alternative means of effecting the sterilization. This technique is one method by which populations of animals, especially insects, can be managed so as to avoid some of the ill effects of wide spectrum pesticides, such as residues in foodstuffs, pest resistance and damage to wildlife.

This book, intended to serve as a basis for continued research and a guide to new workers, is edited and produced by members of the Entomology Research Division of the Agricultural Research Service of the US Department of Agriculture and the Public Health Service. It quotes some 800 references.

After Lindquist's introductory chapter, Knipling sets out the basic criteria for the control of populations of insects and vertebrates by sterilization. He emphasizes the essential difference between the techniques of swamping populations with excess of introduced sterile individuals (usually males) and the sterilization of members of existing natural populations respectively. The latter, which might be achieved by luring adults to sex attractant baits containing suitable chemosterilants, offers a "bonus" over a corresponding level of kill by a conventional insecticide because of the adverse effect of the sterilized insects on the productivity of the rest of the population. The continued existence of the sterilized animals must be tolerated for their long term effect on the population, but this may not always be acceptable to those suffering from the immediate attacks of pests.

Knipling stresses throughout the need for thorough studies of the biology, behaviour, ecology and population dynamies of each pest population as do La Brecque, writing on laboratory testing procedures (third chapter), and Weidhaas, on field development and evaluation (sixth chapter). They all point out that success is dependent on the sterilized male insect being equal in behaviour and sexual performance to the normal wild males.

La Chance, North and Klassen (fourth chapter) describe various types of sterility in the male and infecundity and infertility in the female induced by chemosterilants. They consider the most useful compounds are those, such as alkylating agents, which eause sterility in the male by breaking chromosomes during sperm production without having somatic effects. The zygote produced by the fertilized female fails to develop beyond a few cell divisions.

In the fifth chapter Turner deals with the detailed biochemistry of a number of compounds, and in the seventh chapter Hayes discusses the toxicological aspects, pointing out that because of the nature of these agents their practical use must be strictly controlled. $\mathrm{He}$ hopes, however, that research on inscct reproduction might produce compounds which could render insects sterile but be of insignificant toxic action to man.

The first practical application of ehemosterilants is in preventing the spread of the Mexican fruit fly (Anastrepha ludens (Loew)) from Mexico to California by the release of male flies sterilized by the dipping of pupae in TEPA (an alkylating agent). This book indicates the lines on which research should proceed so that chemosterilants may take their proper place in integrated control programmes. John A. Freeman

\section{NEW ORGANS FOR OLD}

\section{Human Transplantation}

Edited by Felix T. Rapaport and Jean Dausset. Pp. xvii + 728. (Grune and Stratton: New York and London, 1968.) $\$ 38.50$.

The title of this massive and well documented volume is unfortunate. Although references to human transplantation occupy most of the volume, there are whole chapters, such as cardiac transplantation, which are entirely about animal experimentation. In any case, most authors have resorted to evidence provided by animal experimentation, and this is very proper.

This volume is an up to date account by well known authorities on nearly every aspect of transplantation. Biochemistry and enzymology of the transplanted organs 